\title{
Ultrafine-Grained High Strength Cu-Ni-Si Alloys
}

\author{
Igor Altenberger ${ }^{1, a^{*}}$, Hans-Achim Kuhn ${ }^{1, b}$, Mozhgan Gholami-Kermanshahi ${ }^{2, c}$, \\ Mansour Mhaede ${ }^{2, \mathrm{~d}}$, Manfred Wollmann ${ }^{2, \mathrm{e}}$, Lothar Wagner ${ }^{2, \mathrm{f}}$ \\ ${ }^{1}$ Wieland-Werke AG, Graf-Arco-Str. 36, 89079 UIm, Germany \\ ${ }^{2} \mathrm{TU}$ Clausthal, Institute of Material Science and Materials Technology, \\ Agricolastr. 6, 38678 Clausthal-Zellerfeld, Germany \\ aigor.altenberger@wieland.de, bachim.kuhn@wieland.de, \\ cmozhgan.gholami.kermanshahi@tu-clausthal.de, ${ }^{\mathrm{d}}$ mansour.mhaede@tu-clausthal.de, \\ emanfred.wollmann@tu-clausthal.de, 'lothar.wagner@tu-clausthal.de
}

Keywords: copper alloy, swaging, UFG, electrical conductivity, fatigue

\begin{abstract}
Ultrafine-grained (UFG) pure copper has been in the focus of materials scientists over the last two decades, however ultrafine-grained high-strength copper alloys have scarcely been processed or characterized so far industrially.

In this contribution, UFG copper alloys, especially $\mathrm{Cu}-\mathrm{Ni}-\mathrm{Si}$ alloys, being well known as ideal materials for electromechanical connectors, springs and leadframes, are presented. Precipitation hardened $\mathrm{Cu}-\mathrm{Ni}$-Si alloys are a well established and technologically important class of materials for a wide range of applications where high strength and good conductivity are required. Yield strength and fatigue properties of metallic alloys can be significantly enhanced by severe plastic deformation methods. In contrast to other strengthening methods such as solid solution hardening, severe plastic deformation leads to a weaker decrease of electrical conductivity and is therefore a means of enhancing strength while maintaining acceptable conductivity for current bearing parts and components. Characterization of these materials after severe plastic deformation by swaging, wire drawing and subsequent aging was carried out using conductivity-, hardness- and tensile tests as well as highly-resolved microstructural characterization methods.

The results reveal that UFG low alloyed copper alloys exhibit impressive combinations of properties such as strength, conductivity, high ductility as well as acceptable thermal stability at low and medium temperatures. By a subsequent aging treatment the severely plastically deformed microstructure of $\mathrm{Cu}-\mathrm{Ni}$-Si alloys can be further enhanced and thermal stability can profit from grain-boundary pinning by precipitated nanoscale nickel silicides.
\end{abstract}

\section{Introduction}

Precipitation hardened $\mathrm{Cu}-\mathrm{Ni}$-Si alloys are a well established and technologically important class of materials for a wide range of applications where high strength and good conductivity are required [1,2]. In contrast to other strengthening methods such as solid solution hardening, severe plastic deformation leads only to a weak decrease of conductivity and is therefore a means of enhancing strength while maintaining acceptable conductivity for current bearing parts and components. By a subsequent aging treatment the severely plastically deformed microstructure can be further enhanced and thermal stability can profit from grain-boundary pinning by precipitated nanoscale nickel silicides.

Similar to Equal Channel Angular Pressing (ECAP), swaging (or rotary swaging) and subsequent precipitation hardening is a simple method for producing ultra fine grained precipitation hardened copper alloys. Swaging is suitable for producing continuous semi-finished materials such as wires. 


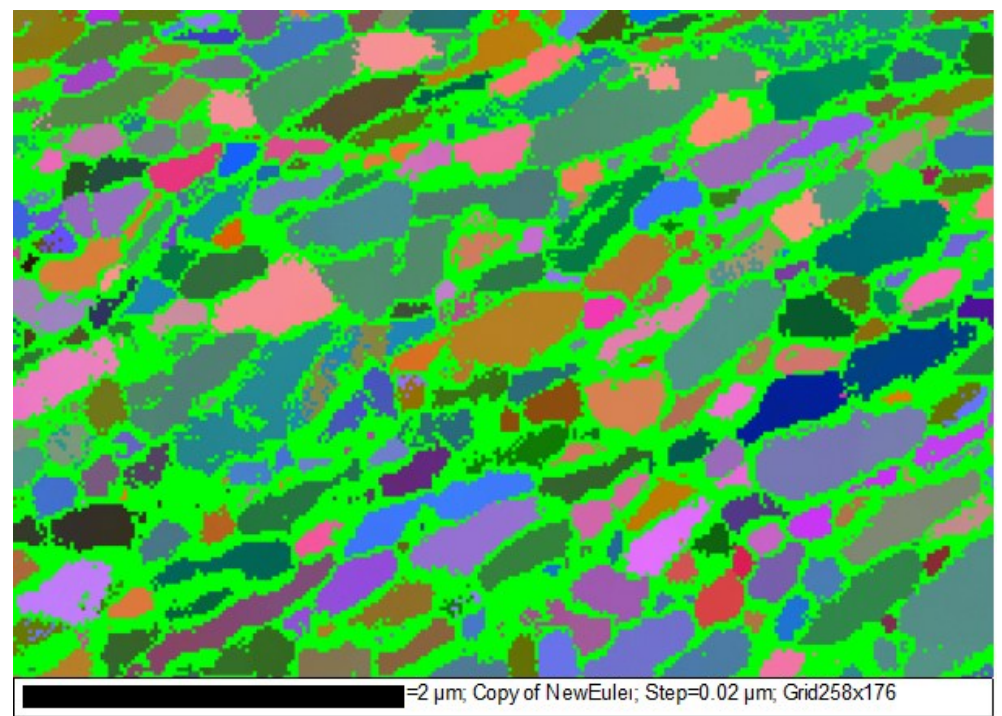

Fig. 1: Uncorrected EBSD-mapping (Euler angles) of ultra-fine grained CuNi3Si1Mg

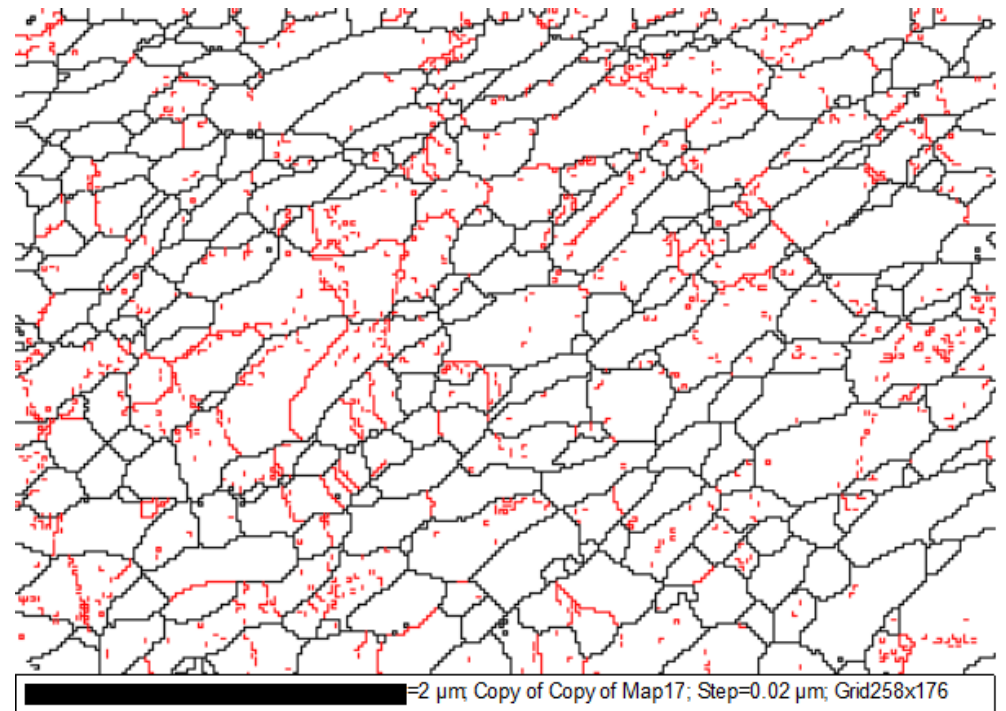

Fig. 2: High- and low-angle grain boundaries in ultrafine-graine $\mathrm{CuNi3Si1Mg}$ (grain boundaries reconstructed)

\section{Results and discussion}

Figs. 1 and 2 exhibit the grain structure of ultra fine grained $\mathrm{CuNi3Si1Mg}$ as obtained by electron backscattering diffraction (EBSD) in the scanning electron microscope (SEM). Optimized severe plastic deformation of wires by swaging with sufficiently high cold work leads to ultra fine grained microstructures exhibiting grain sizes of 0.2 to 0.5 microns after peak aging at $450^{\circ} \mathrm{C} / 1 \mathrm{~h}$. It can be confirmed by misorientation measurements using EBSD that the observed grain boundaries in swaged CuNi3SilMg (UNS-designation 70250) wire (diameter 2,7 mm) are in fact high-angle grain boundaries (misorientation between adjacent grains $>10^{\circ}$ ). In addition, within the ultra fine grains some low-angle grain boundaries (red colour, Fig. 2) can be detected by EBSD.

Through a combination of swaging and optimized precipitation hardening, an ultra fine grained precipitation hardened grain structure can be generated with nanoscale Ni-silicide precipitates situated predominantly at or near grain boundaries (Fig. 3), thus pinning the grain boundaries and enhancing the thermal stability at elevated temperatures. The mechanical properties of ultra-fine

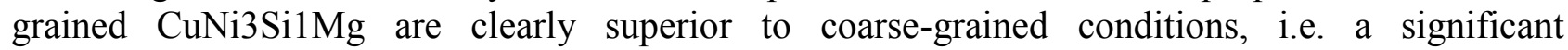
improvement of the elongation to fracture from $7 \%$ to $14 \%$ was measured for the ultra fine grained microstructure as compared to the condition with the conventional grain size [3]. 


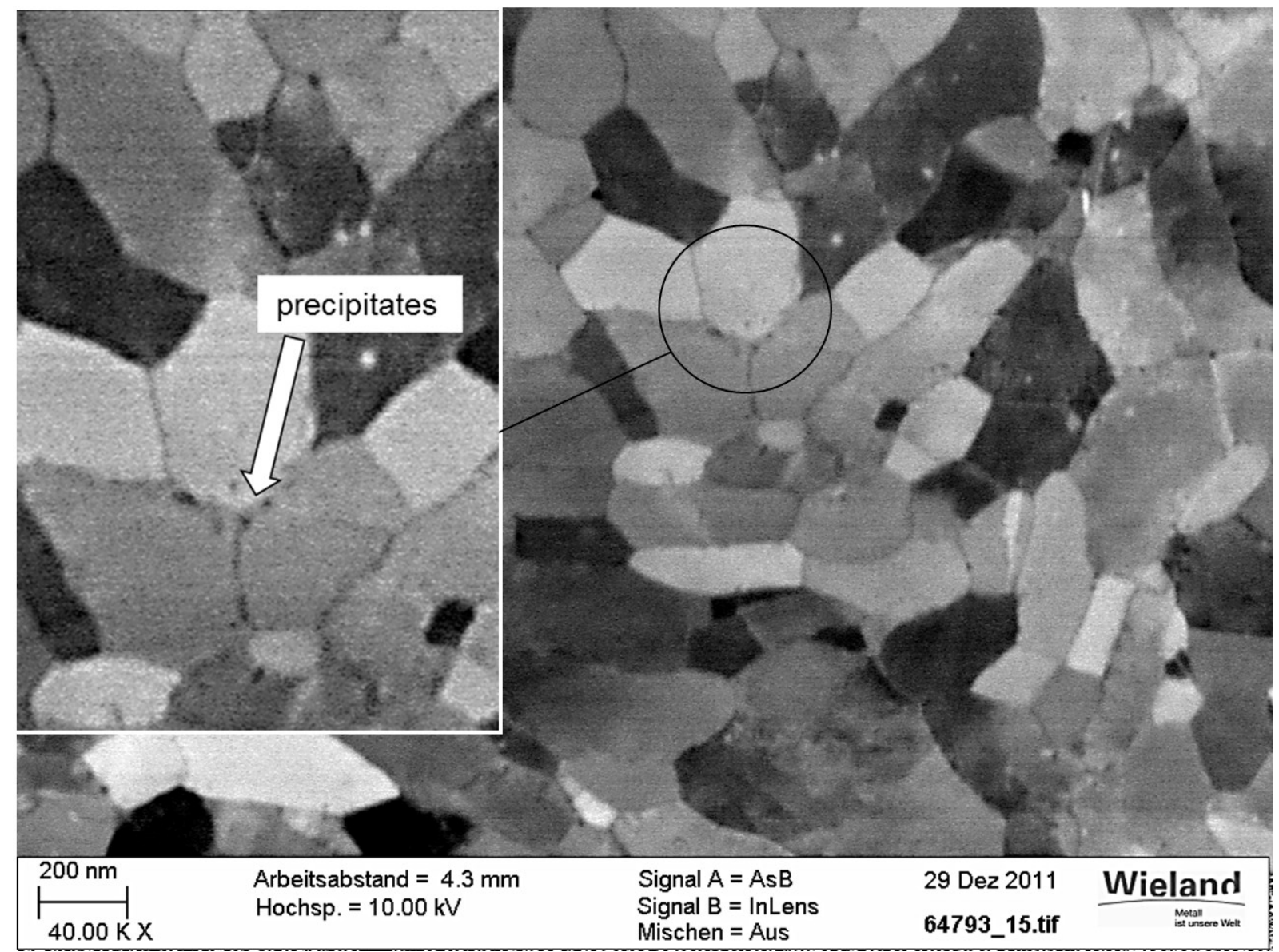

Fig. 3: Electron Channeling Contrast Imaging (ECCI)-picture of ultrafine grained CuNi3Si1Mg in the peak-aged condition exhibiting nanoscale Ni2Si-precipitates at grain boundaries

Eventually, tensile strengths of 900-1000 MPa (hardness of 250-280 HV1) are routinely possible for $\mathrm{Cu}-\mathrm{Ni}-\mathrm{Si}$ alloys, if subsequent swaging, precipitation hardening and cold work (e.g. by wire drawing) are applied (Fig. 4). For thin Cu-Ni-Si-wires, after drawing, more than $50 \%$ of the hardening is ascribed to precipitation hardening, the remaining hardening effect is almost evenly distributed between Hall-Pech-hardening and work hardening. Compared to conventional strip material, the strength increase by ultrafine grains is only moderate (Fig. 4). This is due to the fact, that in severely cold rolled conventional strip also a high density of subgrain boundaries in addition to work hardening is created, which also leads to effective dislocation obstacles. On the other hand, the UFG structure is affiliated with superior ductility as compared to conventional strip, i.e. in $7 \mathrm{~mm}$ swaged wires elongations to fracture of $14 \%$ at tensile strengths of $850 \mathrm{MPa}$ were measured.

Higher nickel contents or the addition of chromium lead to additional hardening as demonstrated for the alloy $\mathrm{CuNi}$ Si2Cr. In contrast to high strength single phased bronzes, the electrical conductivity of $\mathrm{Cu}-\mathrm{Ni}-\mathrm{Si}$ alloys remains attractive and typically exhibits values of $30-35 \%$ IACS after swaging. It is important to note, that every copper alloy requires specific optimized swaging conditions, i.e. CuNi3Si1Mg exhibits the highest hardness increase after swaging with a logarithmic strain of 2.5. In terms of hardness, increasing cold work leads to a saturated condition or even softening (Fig. 5).

Fig. 6 shows the change of electrical conductivity of the swaged and non-swaged condition during aging at $450{ }^{\circ} \mathrm{C}$. Owing to continuous diffusion of alloying elements $\mathrm{Ni}$ and $\mathrm{Si}$ from the solid solution copper matrix into the precipitates, the scattering of electrons by the strain fields of solute atoms is diminished and the conductivity increases. It is noteworthy, that already after 10 minutes the conductivity of the swaged condition is slightly higher than the conductivity of the non-deformed condition at this temperature. Obviously, the diffusion of solute elements is significantly accelerated by fast diffusion paths such as high- and low angle boundaries which are prevalent in the swaged condition. Throughout the further aging process the electrical conductivity 
of the swaged condition stays superior to the conductivity of the non-deformed condition [4,5]. This difference amounts up to 8\% IACS in severely over-aged specimens, possibly being caused also by recrystallization which drastically reduces the grain boundary area in the swaged and severely overaged condition. For comparison, standardized commercial $\mathrm{CuNi3Si1Mg}$ strips typically have electrical conductivities of 35-45\% IACS.

In addition to excellent quasistatic strength, optimized swaging plus consecutive aging leads to a marked increase of the $10^{7}$-fatigue endurance strength [4]. Moreover, if swaged and subsequently aged $\mathrm{CuNi3SilMg}$ is additionally mechanically surface treated (by shot peening, laser-shock peening or deep rolling), the fatigue endurance strength exceeds $400 \mathrm{MPa}$. The only copper alloys exhibiting higher strengths than $\mathrm{Cu}-\mathrm{Ni}$-Si alloys are high-alloyed or spray-formed copper alloys and $\mathrm{Cu}-\mathrm{Be}$ alloys $[6,7,8]$. Minor improvements of strength in $\mathrm{Cu}-\mathrm{Ni}-\mathrm{Si}$ alloys can also be achieved by additions of $\mathrm{Cr}$, $\mathrm{Al}$ or Ti $[9,10]$.

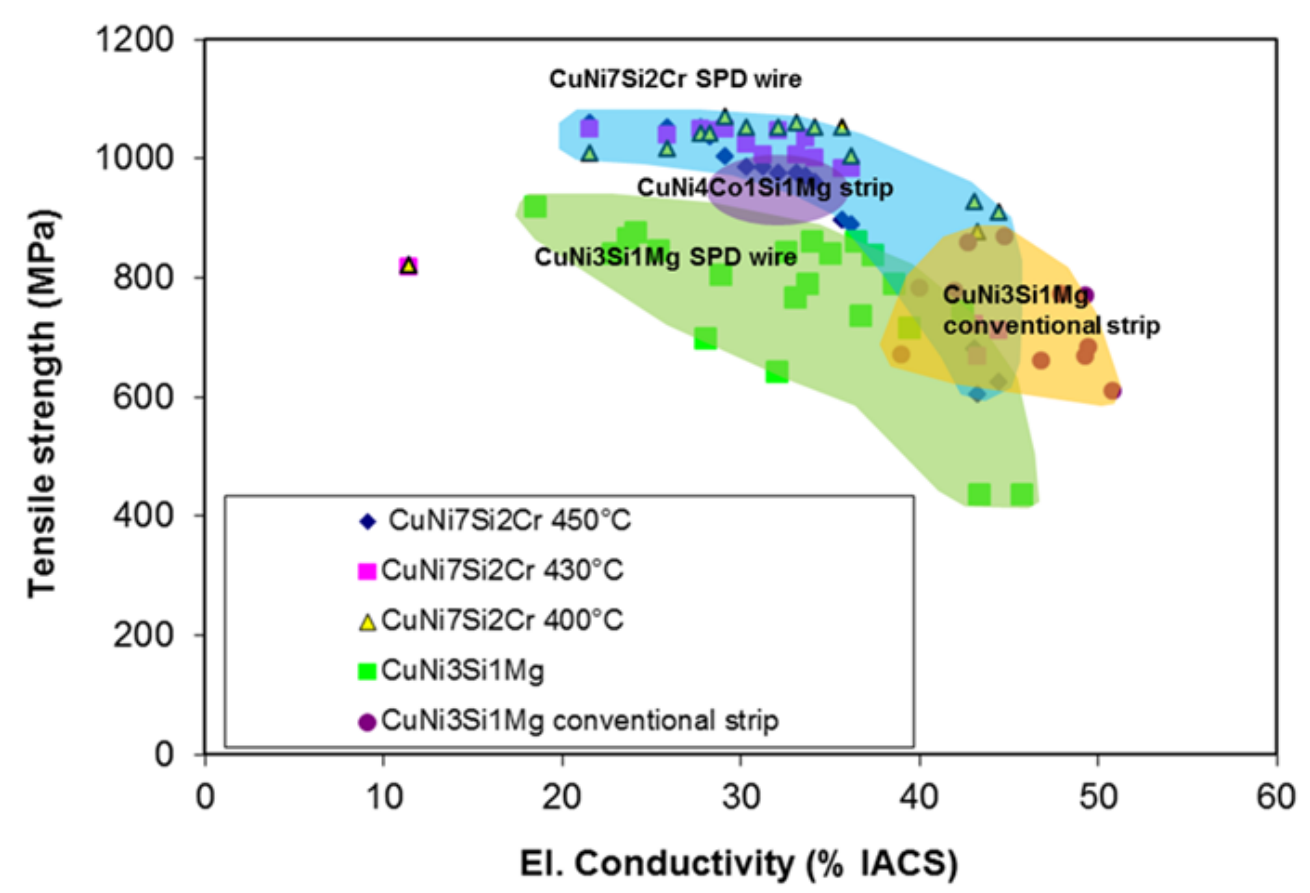

Fig. 4: Tensile strength and electrical conductivity of ultra-high-strength $\mathrm{Cu}-\mathrm{Ni}$-Si alloys

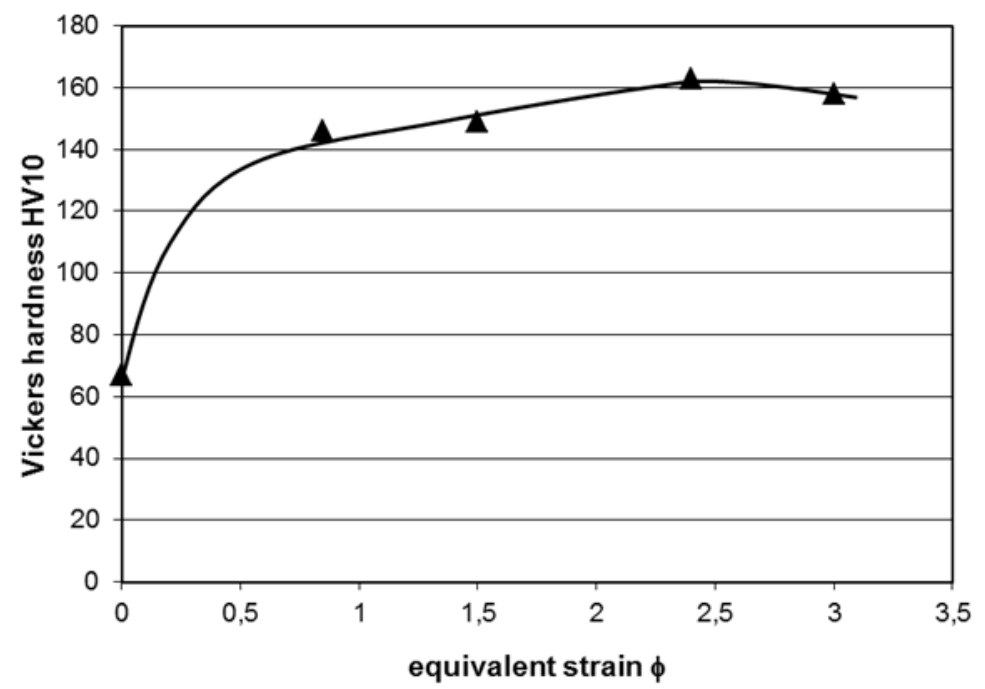

Fig. 5: Effect of deformation degree on Vickers hardness of swaged CuNi3Si1Mg (prior to swaging, rods were hot extruded and solution treated at $800{ }^{\circ} \mathrm{C} / 2 \mathrm{~h}$ ) 


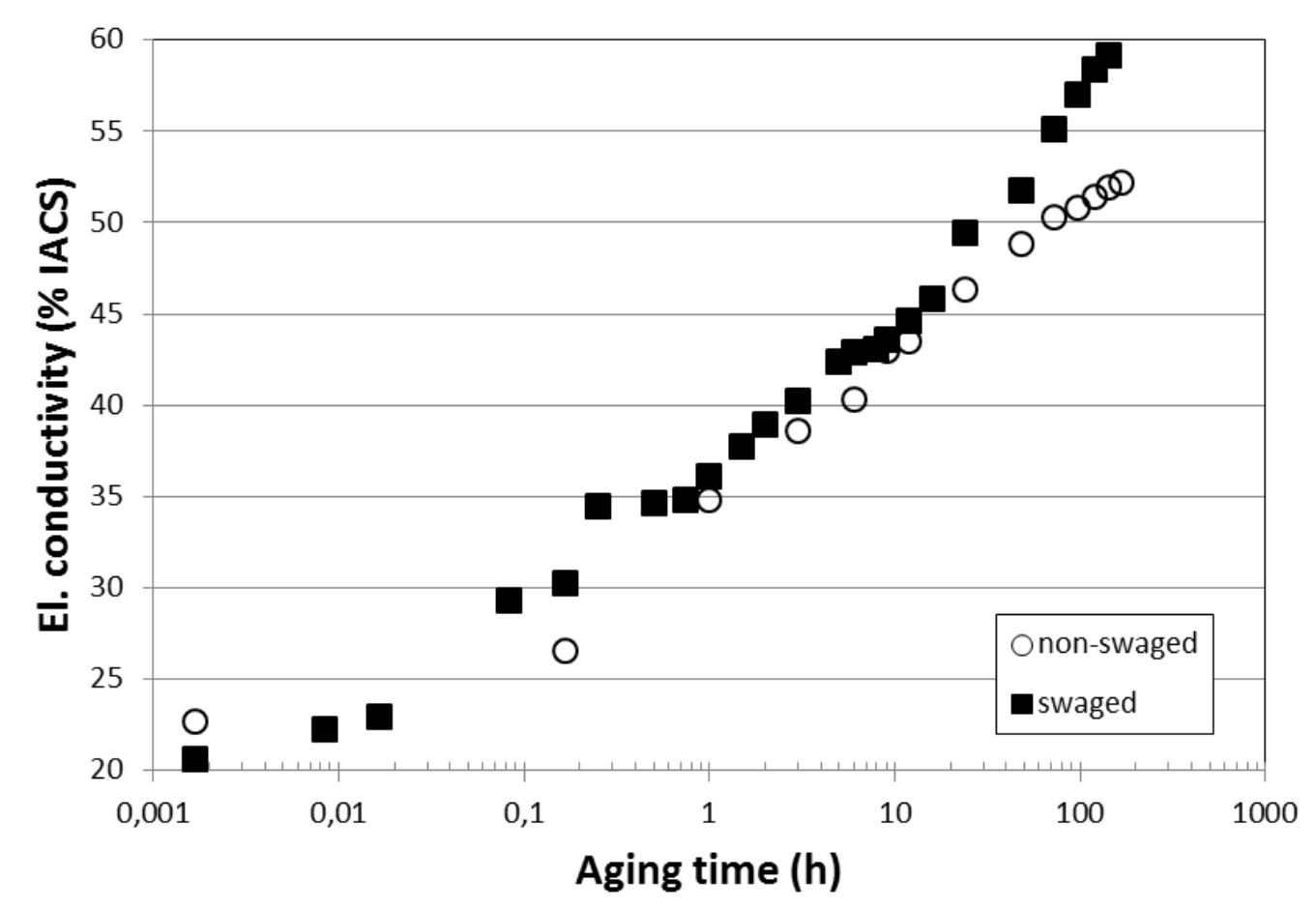

Fig. 6: Conductivity vs. aging time for swaged (UFG) and coarse-grained $\mathrm{CuNi3Si1Mg}$ $\left(\mathrm{T}=450{ }^{\circ} \mathrm{C}\right)$

\section{Summary}

Rotary swaging is a very efficient processes to generate high strength through ultra fine grains, especially if it is combined with precipitation hardening. Thus $\mathrm{Cu}-\mathrm{Ni}-\mathrm{Si}$ materials with very fine grain sizes in the range $0,2-2 \mu \mathrm{m}$ can be produced. EBSD and electron channeling contrast in the SEM are very helpful tools to characterize such microstructures [11].

Swaging and accumulative roll bonding, typically lead to a maximum hardness at a logarithmic strain or deformation degree of 2.5 and 5 , respectively.

Severely plastically deformed (swaged or accumulative roll bonded) and subsequently precipitation hardened $\mathrm{Cu}-\mathrm{Ni}-\mathrm{Si}-\mathrm{Mg}$ alloys show only slightly earlier thermal softening than conventionally processed microstructures of $\mathrm{Cu}-\mathrm{Ni}-\mathrm{Si}$ alloys. The thermal stability of ultra fine grained $\mathrm{CuNi3Si1Mg}$ is significantly enhanced as compared to pure copper. Grain boundary pinning by nanoscopically small precipitates is suggested as the beneficial mechanism.

A crucial role is ascribed to the artificial aging treatment after the severe plastic deformation. At $300{ }^{\circ} \mathrm{C}$ no over-aging was detected within 200 hours. For short time exposure $(1 \mathrm{~h})$ the grain structure is fairly stable up to $400{ }^{\circ} \mathrm{C}$. In addition to enhanced ultimate tensile- and yield strength (with possible tensile strength $>1000 \mathrm{MPa}$ for $\mathrm{CuNi}$ Si2 $\mathrm{Cr}$ ), also the fatigue behavior in the High Cycle Fatigue (HCF)-regime was significantly improved by the UFG-structure in the swaged plus peak-aged condition close to the surface.

It should be emphasized that $\mathrm{Cu}-\mathrm{Ni}-\mathrm{Si}-(\mathrm{Cr})$ alloys, whether ultrafine-grained or just fine-grained, are not genuine $\mathrm{CuBe} 2$-replacements, since they are unable to reach tensile strengths of 1400-1600 MPa. The stress relaxation resistance of Cu-Ni-Si alloys is excellent and almost at the same level than $\mathrm{Cu}-\mathrm{Be} 2$. However, their metal prices are significantly lower than for $\mathrm{CuBe} 2$ or $\mathrm{CuBe} 2 \mathrm{CoNi}$. In addition, in their strongest points, namely high conductivity at high strength, high ductility and bendability, as well as high fracture toughness, $\mathrm{Cu}-\mathrm{Be}$ alloys have a tough stand to compete with them. Due to these properties, for many applications, $\mathrm{Cu}-\mathrm{Ni}-\mathrm{Si}-(\mathrm{Cr})$ alloys are the better alternative to the less ductile and less conductive $\mathrm{CuNi15Sn8}$ to "replace" $\mathrm{Cu}-\mathrm{Be}$ alloys. 


\section{Acknowledgement}

Experimental support by Dr.-Ing. D. Vucic-Seele, M. Fünfer, M. Domitrovic and J. Bayerl is kindly acknowledged.

\section{References}

[1] H.-A. Kuhn, I. Altenberger, A. Käufler, H. Hölzl, M. Fünfer, M., Properties of high performance alloys for electromechanical connectors, In: Copper Alloys - Early Applications and Current Performance - Enhancing Processes (Ed. L. Collini), Intech, 2012, p. 52.

[2] J. Kinder, D. Huter, TEM-Untersuchungen an höherfesten und elektrisch hochleitfähigen CuNi2Si-Legierungen, Metall 63 (2009) 298.

[3] I. Altenberger, H.-A. Kuhn, M. Mhaede, M. Gholami, L. Wagner, Wie viel NANO steckt in Kupfer - ein klassischer Werkstoff im 21. Jahrhundert, Metall, 66 (2012) 500.

[4] I. Altenberger, H.-A-Kuhn, M. Gholami, M. Mhaede, L. Wagner, Ultrafine-grained precipitation hardened copper alloys by swaging or accumulative roll bonding, Metals 5 (2015) 763.

[5] M. Gholami, I. Altenberger, J. Vesely, H.-A. Kuhn, M. Wollmann, M. Janecek, L. Wagner, Effects of severe plastic deformation on transformation kinetics of precipitates in CuNi3Si1Mg, Mater. Sci. Eng. 676 A (2016) 156.

[6] I. Altenberger, M. Mhaede, H.A. Kuhn, Y. Sano, L. Wagner, Effect of swaging and mechanical surface treatments on the mechanical properties of the spray-formed ultra high strength copper alloy CuMn20Ni20, In: ICSP12 - Proc. $12^{\text {th }}$ Int. Conf. on Shot Peening (Ed. L. Wagner), Goslar, 2014, p. 202.

[7] I. Altenberger, S. Heinrichs, H.-A. Kuhn, In: Proc. EMC-2017, Microstructure and properties of ultra high strength high-alloyed and quasi-equiatomic $\mathrm{Cu}-\mathrm{Al}-\mathrm{Mn}$ alloys, Leipzig, 2017, in print.

[8] I. Altenberger, H.-A. Kuhn, H. R. Müller, M. Mhaede, M. Gholami, L. Wagner, Material Properties of High-Strength Beryllium-free Copper Alloys, Int. J. Materials and Product Technology 50 (2015) 2, 124.

[9] J. Y. Cheng, B. B. Tang, F. X. Yu, B. Shen, Evaluation of nanoscaled precipitates in a Cu-NiSi-Cr alloy during aging, Journal of Alloys and Compounds 614 (2014) 189.

[10]Q. Lei, Z. Li, T. Xiao, Y. Pang, Z. Q. Xiang, W. T. Qiu, Z. Xiao, A new ultrahigh strength CuNi-Si alloy, Intermetallics 42 (2013) 77.

[11]I. Altenberger, H.-A. Kuhn, M. Gholami, M. Mhaede, L. Wagner, IOP Conf. Series: Materials Science and Engineering 63 (2014) 012135. 